Research Article

\title{
Trimetallic@Cyclodextrin Nanocomposite: Photocatalyst for Degradation of Amoxicillin and Catalyst for Esterification Reactions
}

\author{
Gaurav Sharma ${ }^{(D,},{ }^{1,2,3}$ Alberto García-Peñas, ${ }^{4}$ Mu. Naushad ${ }^{D},{ }^{5}$ Amit Kumar, ${ }^{1,2}$ \\ Mika Sillanpää (iD, ${ }^{6}$ and Forian J. Stadler ${ }^{1}$ \\ ${ }^{1}$ College of Materials Science and Engineering, Shenzhen Key Laboratory of Polymer Science and Technology, \\ Guangdong Research Center for Interfacial Engineering of Functional Materials, \\ Nanshan District Key Laboratory for Biopolymers and Safety Evaluation, Shenzhen University, Shenzhen 518055, China \\ ${ }^{2}$ International Research Centre of Nanotechnology for Himalayan Sustainability (IRCNHS), Shoolini University, \\ Solan 173212, Himachal Pradesh, India \\ ${ }^{3}$ School of Science and Technology, Glocal University, Saharanpur, India \\ ${ }^{4}$ Departamento de Ciencia e Ingeniería de Materiales e Ingeniería Química (IAAB), Universidad Carlos III de Madrid, \\ Leganés 28911, Madrid, Spain \\ ${ }^{5}$ Department of Chemistry, College of Science, King Saud University, P.O. Box 2455, Riyadh 11451, Saudi Arabia \\ ${ }^{6}$ Department of Biological and Chemical Engineering, Aarhus University, Nørrebrogade 44, Aarhus C 8000, Denmark
}

Correspondence should be addressed to Gaurav Sharma; gaurav8777@gmail.com and Mu. Naushad; naushadksu@rediffmail.com Received 5 February 2021; Accepted 16 August 2021; Published 8 September 2021

Academic Editor: Liviu Mitu

Copyright (c) 2021 Gaurav Sharma et al. This is an open access article distributed under the Creative Commons Attribution License, which permits unrestricted use, distribution, and reproduction in any medium, provided the original work is properly cited.

\begin{abstract}
The industry is looking for new materials which can respond to specific applications that exclusively advance materials can provide. In this context, nanoparticles and nanocomposites opened an interesting method for designing specific properties which can be modulated according to the requirements. The preparation of biomolecules supported trimetallic nanoparticles and some other derives is a good example of the complex systems that can be designed for getting exclusive properties. This study is based on the preparation of new cyclodextrin supported $\mathrm{Fe} / \mathrm{La} / \mathrm{Zn}$ trimetallic nanocomposite by the microemulsion technique. Photocatalytic degradation of amoxicillin was performed using cyclodextrin-Fe/La/Zn. 78\% of amoxicillin photodegradation along 4 hours of photoirradiation was achieved. Finally, the catalytic nature of new material was explored for oxidation and esterification reactions. The present study revealed that this advanced multifunctional nanomaterial can be successfully employed for environmental remediation and catalytic activities.
\end{abstract}

\section{Introduction}

The use of some nanomatrices made up of oxide and metallic nanoparticles have important applications in areas such as electronics and catalysis. These numerous uses can be understood because nanoparticles are the simplest form of structures having size in the nanometer range that allows getting multipurpose features as extensive availability, rich functionalities, better biocompatibility, ability for controlled release of drugs, and targeted drug delivery [1-3].
In general, nanoparticles are classified in two categories according to their nature, that is, inorganic nanoparticles and organic nanoparticles. The inorganic nanoparticles embrace noble metal nanoparticles (such as silver and gold), semiconductor nanoparticles (such as zinc oxide, copper oxide, and titanium dioxide), magnetic nanoparticles, and bi or trimetallic nanoparticles [4-7]. In contrast, organic nanoparticles mainly contain polymeric nanoparticles and carbon nanoparticles. There are several methods for the preparation of nanoparticles, but the microemulsion 
technique has been mainly used because of its outstanding control on the reaction parameters, which can lead through specific modification of materials properties [8-11].

The nanoparticles showed potential results such as catalysts for fuel cells and in photocatalytic devices. In addition, some nanoparticles were also tested as catalytic systems for producing numerous chemicals. Nowadays, the use of platinum nanoparticles as automotive catalytic converters can offer a very high surface area, which could reduce the amount of platinum normally required. Nevertheless, some shortcomings should be considered, such as these could spontaneously combust if methane is mixed with the ambient air.

Nanoparticles can open a new perspective in the field of antimicrobials, due to pathogenic microorganisms acquiring resistance to diverse antibiotics, which could derive in a serious health issue [12-14]. Nanoparticles based on silver exhibits excellent antibacterial activity against various infections and can provide other kind of features such as antiviral property and its antioxidant nature which can be very useful against neurological diseases and cancer $[15,16]$. Furthermore, metal nanoparticles with antimicrobial activity can be involved in diverse applications like waste water treatment, biomedical and surgical devices, synthetic textiles, food packaging, and processing $[1,3,9,15-20]$.

On the other hand, the properties of nanoparticles can be increased or improved through the preparation of nanocomposites, which can play an important role as drug carriers due to their improved loading capabilities, higher stability, and great control over physicochemical properties. In addition, these materials can provide an excellent biocompatibility. Biodegradability and low toxic nature, which can be very useful for pharmaceutical applications [21, 22]. At the present time, some polymer matrix composites are based on exfoliated clay, carbon nanofibers, nanocrystalline metals or graphene, carbon nanotubes, and carbon nitride, as these can provide new specific characteristics especially important for some applications such as drug delivery, chromatography, photocatalysis, or environmental remediation [23-29].

On the other hand, various biopolymers and gums such as cellulose, pectin, chitin, guar gum, chitosan, and gum arabica have been successfully used to fabricate diverse composite [30, 31]. The bi or trimetallic nanocomposites can be used for the degradation of nonbiodegradable organic contaminants and other compounds [32-34]. The adsorption, photocatalysis, ion exchange, and classic homogeneous Fenton oxidation are few of the widely used processes for the treatment of wastewater which contains organic synthetic dyes, pesticides, personal care products, and pharmaceuticals [35-39].

The use of cyclic oligosaccharides, such as cyclodextrins, is extended due to its excellent properties associated with its ability for preparing of supramolecular structures. As result, a large number of publications are produced each year where cyclodextrin is involved $[31,40,41]$. There are three kinds of cyclodextrins, which are known as $\alpha$-cyclodextrin, $\beta$-cyclodextrin, and $\gamma$-cyclodextrin, according to its generation.
In general, $\beta$-cyclodextrin is the most used because of its common availability and its low price [42, 43].

Then, nanocomposites can offer multiple applications; thus, this work is focused on the preparation of cyclodextrin that supported $\mathrm{Fe} / \mathrm{La} / \mathrm{Zn}$ trimetallic nanocomposite using the microemulsion method. The resulting material has been characterized by UV spectroscopy (UV), Fourier transformer infrared spectroscopy (FTIR), transmission electron microscopy (TEM), X-ray diffraction spectroscopy (XRD), and scanning electron microscopy (SEM). Some applications as the study of the photodegradation of antibiotic and electrocatalytic nature of synthesized material have been explored for esterification reactions.

\section{Experimental Part}

2.1. Materials. Nitrate of iron, zinc, lanthanum, sodium borohydride, butanol, acetic acid, and isopropyl alcohol (CDH Pvt. Ltd., India), cyclodextrin, amoxicillin, and Tween 80 (S.D. Fine Chemical Pvt. Ltd., India), and benzyl alcohol and ethanol (Loba Chemie Pvt. Ltd., India) were used as received.

2.2. Fabrication of $\beta-C D-F e / L a / Z n$ Nanocomposite. The $\beta$-CD-Fe/La/Zn nanocomposite was fabricated by the microemulsion technique. For that purpose, three microemulsions were prepared before getting the final nanocomposite. First, microemulsion was made using a ratio 3 water: 2 cyclohexane; into this $0.1 \mathrm{M}$ nitrates of iron, lanthanum and zinc were mixed (volume by volume) ratio (Scheme 1). Then, the stabilization of microemulsion was achieved by addition of Tween 80 $(3 \mathrm{~mL})$ as discussed in our previous work [44]. A second microemulsion was prepared adding $0.01 \mathrm{M}$ of sodium borohydride by preserving the same conditions as in the first microemulsion. Then, $0.01 \mathrm{M}$ solution of cyclodextrin prepared in distilled water was added to the first microemulsion. The second microemulsion was added to above mixture dropwise with constant stirring and after that stirred for 3 hours at room temperature. The resulting nanocomposite was centrifuged, washed via water for eradicating impurities, and dried at $50^{\circ} \mathrm{C}$ for 4 hours in oven.

2.3. Characterization. Diverse characterization methods were used for the analysis of the resulting nanocomposite. Fourier transform infrared (FTIR) spectrum was obtained in the wave number ranged from 4000 to $400 \mathrm{~cm}^{-1}$. UV-Vis spectrophotometer (Systronics 2202) was used for the analysis of the band gap and degradation studies. The X-ray diffraction (XRD, Panalytical's X'Pert Pro) study was performed in the reflectance mode with $\lambda=0.1541837 \mathrm{~nm}$. The SEM images (scanning electron microscope) were acquired at different magnifications (JSM-6100 SEM-microscope) and the TEM images (transmission electron microscope) by Tecnai G2 20 S-TWIN at acceleration voltage $20-200 \mathrm{kV}$. The thermal stability of the samples was checked by 


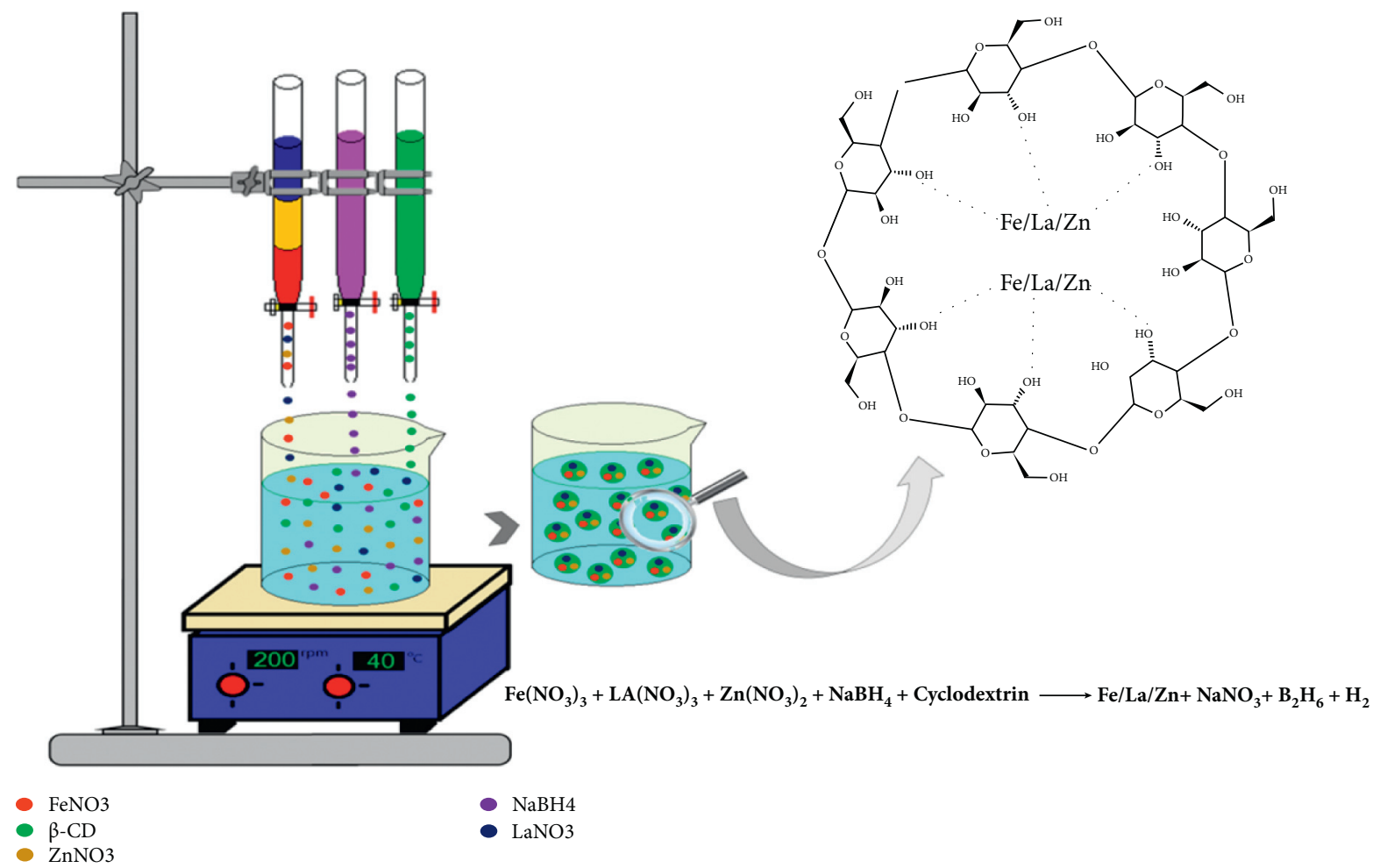

Scheme 1: Synthesis of Fe/La/Zn@ $\beta$-CD trimetallic nanocomposite.

conventional calorimetry and thermogravimetric analysis. A calorimeter (Q200 differential scanning calorimeter) from TA Instruments equipped with a cooling system was used for that purpose. The weight of the nanocomposite measured was around $50 \mathrm{mg}$, and the heating rate applied was $10^{\circ} \mathrm{C} /$ min under nitrogen atmosphere. The thermogravimetric analysis (TGA-TA Instruments Q50) was performed using a heating rate of $20^{\circ} \mathrm{C} / \mathrm{min}$ from 50 to $800^{\circ} \mathrm{C}$ in a nitrogen atmosphere.

2.4. Remediation of Amoxicillin. The photocatalytic activity of $\beta$-CD-Fe/La/Zn nanocomposite was tested for amoxicillin degradation. Solution of amoxicillin was prepared, and $0.1 \mathrm{~g}$ of $\beta-\mathrm{CD}-\mathrm{Fe} / \mathrm{La} / \mathrm{Zn}$ was added. Then, photocatalytic experiments were performed using two kind of conditions: (a) adsorptiondesorption equilibrium was achieved in the dark followed by photocatalysis in sunlight and (b) simultaneous adsorption/ photocatalysis was performed under sunlight. The total volume of the reaction mixture was kept at $200 \mathrm{~mL}$. At precise time breaks, aliquot of $3 \mathrm{~mL}$ was withdrawn from test sets for analysis. The concentration of amoxicillin was logged using the UV-vis spectrophotometer at $248 \mathrm{~nm}$. The percentage degradation was considered by employing following equation [45]:

$$
\text { \%degradation }=\frac{C_{0}-C_{t}}{C_{0}} \times 100,
$$

where $C_{\mathrm{o}}$ is the primary absorbance of amoxicillin and $C_{t}$ is the absorbance of amoxicillin after time $t(\mathrm{~min})$.

Photocatalytic degradation rate for amoxicillin was considered using pseudo-first-order kinetic as follows:

$$
\begin{aligned}
r & =-\frac{d_{c}}{d_{t}}=k_{\mathrm{app}} t, \\
\operatorname{In} \frac{C_{0}}{C_{t}} & =k_{\mathrm{app}} t,
\end{aligned}
$$

where $k$ is the apparent rate constant, $C_{\mathrm{o}}$ is the concentration of amoxicillin afore illumination, and $C_{t}$ is the concentration of amoxicillin at time $t$.

The effect of radical scavengers, silver nitrate (AgNO3), ethylenediaminetetraacetic acid (EDTA), 4-hydroxy-2,2, 6,6-tetramethylpiperidinyloxy (TEMPOL) and tert-butanol on photodegradation was also studied. Chemical oxygen demand (COD) was assessed by Chemetrics low range $(10-150 \mathrm{mg} / \mathrm{L})$ COD vials.

2.5. $\beta-\mathrm{CD}-\mathrm{Fe} / \mathrm{La} / \mathrm{Zn}$ as Catalyst for Esterification. Esterification reactions were performed using acetic acid and alcohol (ratio $2: 1$ ) along with $\beta$-CD-Fe/La/Zn as catalyst. To the above reaction mixture, $10-15 \mathrm{~mL}$ of appropriate solvent such as toluene or cyclohexane was added and refluxed for 2.5 hours at $110^{\circ} \mathrm{C}$. The reaction yield was considered by formula as

$$
\% \text { yield }=\frac{W_{R}-W_{P}}{W_{R}} \times 100,
$$

where $W_{R}$ is the initial weight of reactant and $W_{P}$ is the weight of products formed. 


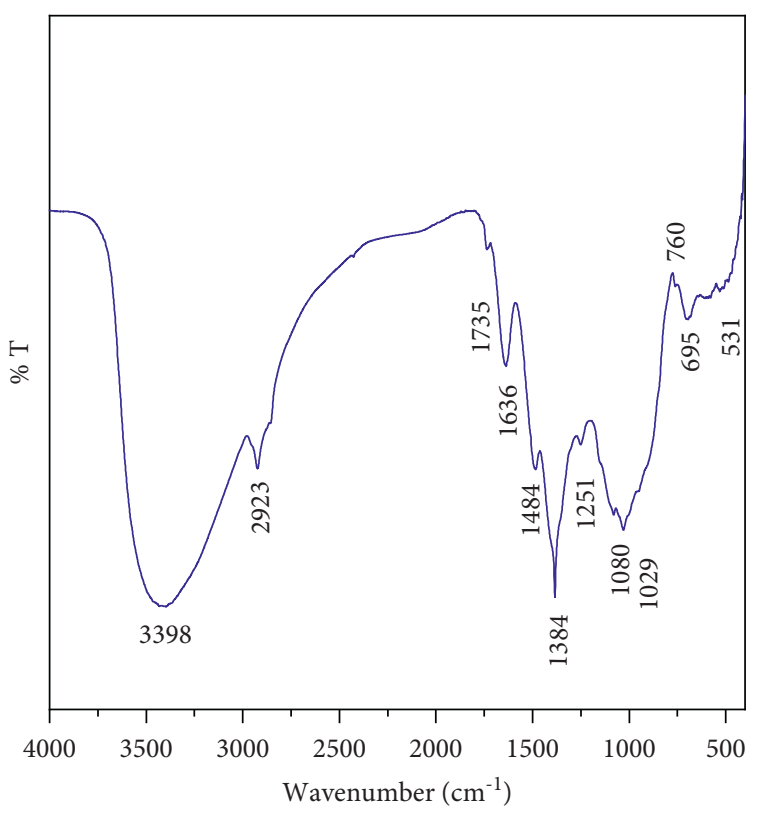

(a)

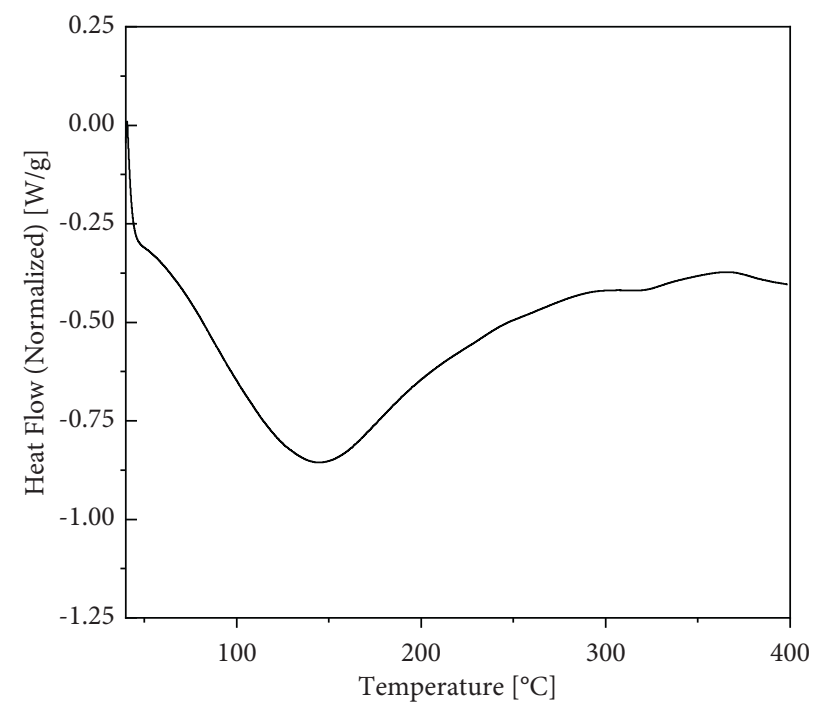

(c)

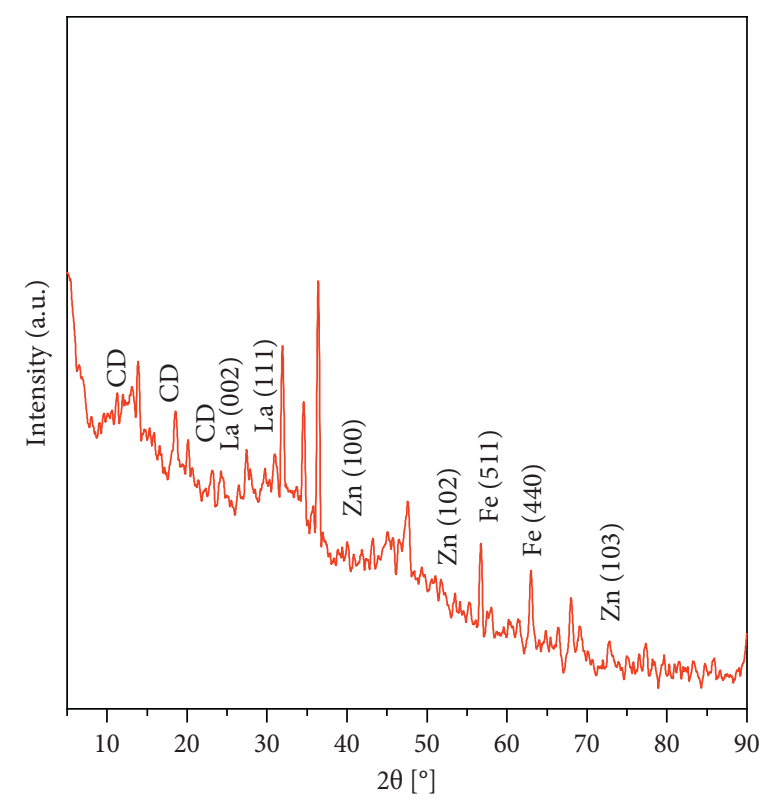

(b)

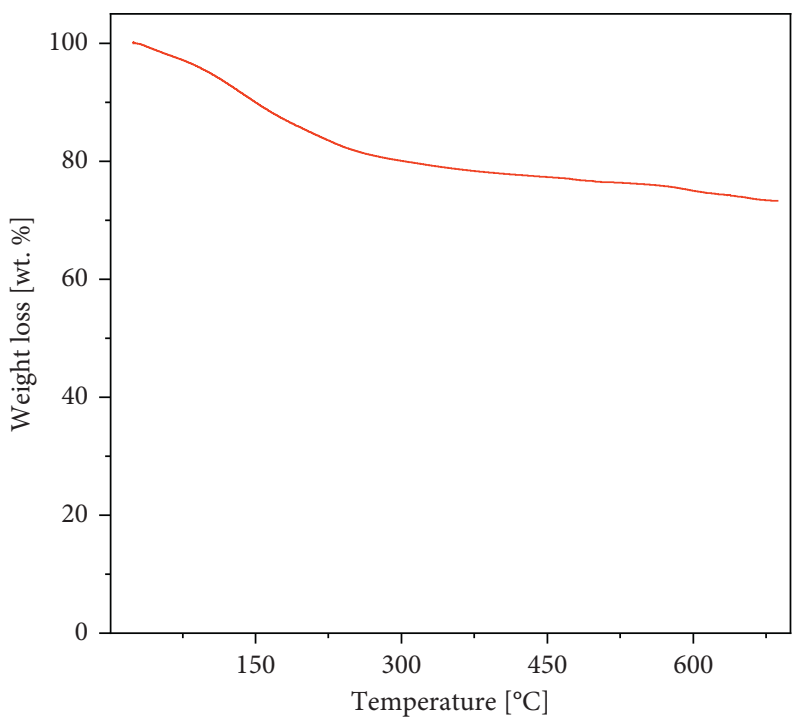

(d)

FIGURE 1: (a) FTIR spectrum, (b) XRD spectrum, (c) calorimetric analysis, (d) and thermal stability for $\beta$-CD-Fe/La/Zn nanocomposite.

\section{Results and Discussion}

3.1. Characterization. The FTIR spectrum of $\beta-\mathrm{CD}-\mathrm{Fe} / \mathrm{La} /$ $\mathrm{Zn}$ is displayed in Figure 1(a) and shows the characteristic peak at $3398 \mathrm{~cm}^{-1}$ associated with the $\mathrm{O}-\mathrm{H}$ stretching mode of the $-\mathrm{OH}$ group $[46,47]$. The peak present at $2923 \mathrm{~cm}^{-1}$ is induced by asymmetric stretching of the $-\mathrm{CH}_{2}$ group [48]. The peak obtained at $1636 \mathrm{~cm}^{-1}$ corresponds to $\mathrm{H}-\mathrm{O}-\mathrm{H}$ bonding of absorbed water. Atmospheric $-\mathrm{CO}_{2}$ groups present in the $\beta-\mathrm{CD}-\mathrm{Fe} / \mathrm{La} / \mathrm{Zn}$ are located at $1384 \mathrm{~cm}^{-1}$.

The peak present at $1735 \mathrm{~cm}^{-1}$ is due to the presence of the $\mathrm{C}=\mathrm{O}$ group, which clearly indicates the binding of cyclodextrin with $\mathrm{Fe} / \mathrm{La} / \mathrm{Zn}$ and confirms the formation of $\beta-\mathrm{CD}-\mathrm{Fe} / \mathrm{La} / \mathrm{Zn}$ [49]. Peak at $1484 \mathrm{~cm}^{-1}$ relates to $\mathrm{C}-\mathrm{H}$ bending, and the peaks existing at $1251 \mathrm{~cm}^{-1}, 1029 \mathrm{~cm}^{-1}$, and $1080 \mathrm{~cm}^{-1}$ are associated with $\mathrm{C}-\mathrm{O}-\mathrm{C}, \mathrm{C}-\mathrm{O}$, and $\mathrm{O}-\mathrm{H}$ bond stretching. The intensity of peaks for $\mathrm{Fe}-\mathrm{O}, \mathrm{Zn}-\mathrm{O}$, and $\mathrm{La}-\mathrm{O}$ was found at $531 \mathrm{~cm}^{-1}, 695 \mathrm{~cm}^{-1}$, and $760 \mathrm{~cm}^{-1}$ due to binding of $\beta$-CD to $\mathrm{Fe} / \mathrm{La} / \mathrm{Zn}[50]$.

The XRD-diffraction spectrum of the synthesized $\beta-\mathrm{CD}-\mathrm{Fe} / \mathrm{La} / \mathrm{Zn}$ nanocomposite is shown in Figure $1(\mathrm{~b})$, where the characteristic peaks displayed at $57.1^{\circ}$ and $62.8^{\circ}$ can be associated with (511) and (440) diffraction planes and are in accordance with the standard JCPDS file no. 65-3107 for iron [51]. The characteristics peaks at $27.40^{\circ}$ and $30.26^{\circ}$ corresponding to (002) and (111) diffraction planes of lanthanum associated with JCPDS card no. 020607 [52]. The presence of zinc displays important diffractions at $39^{\circ}, 54^{\circ}$, and $70^{\circ}$ corresponding to the next 


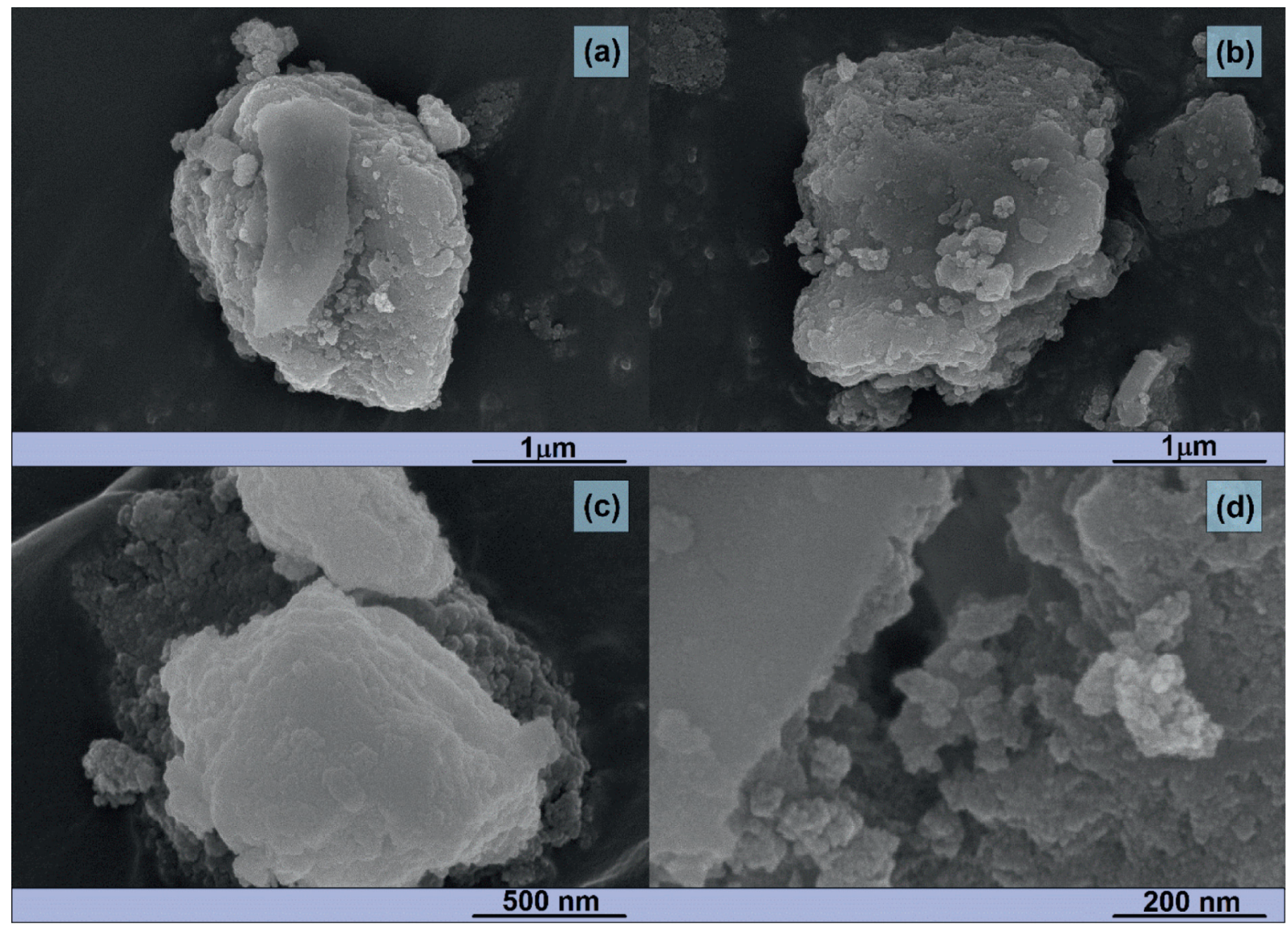

FIgURE 2: SEM images (a)-(d) for $\beta$-CD-Fe/La/Zn nanocomposite at different scales.

planes (100), (102), and (103) corresponding to JCPDS file no. 036-1451 [53]. Finally, the presence of cyclodextrin is confirmed by the characteristic peak displayed at $12.62^{\circ}$, $18^{\circ}$, and $22.54^{\circ}$. The thermal stability of $\beta-\mathrm{CD}-\mathrm{Fe} / \mathrm{La} / \mathrm{Zn}$ nanocomposite was also analyzed using conventional calorimetric and thermogravimetric analysis. First, the calorimetric curve is displayed in Figure 1(c) where two transitions are detected. The main endothermic process exhibits a broad phase over $120^{\circ} \mathrm{C}$ and can be correlated to the release of water. On the other hand, a small phase takes place around $300^{\circ} \mathrm{C}$ which can be associated with the decomposition of $\beta$-CD.

The thermogravimetric analysis of the $\beta-\mathrm{CD}-\mathrm{Fe} / \mathrm{La} / \mathrm{Zn}$ nanocomposite is shown in Figure 1(d). The curve depicts a first deep drop around $100^{\circ} \mathrm{C}$, which is clearly related with the release of water molecules, where the physical adsorbed water reaches the $15 \mathrm{wt} . \%$ of the total amount of the sample. This first deep broad transition leads to the overlapping with a second transition which takes place around $300^{\circ} \mathrm{C}$. The curve follows the same transitions observed in the calorimetry, and consequently, this second transition can be linked with the decomposition of $\beta$-CD. In this context, metallic $\mathrm{Fe} / \mathrm{La} / \mathrm{Zn}$ nanoparticles can be considered more stable as total weight loss observed is not too high, i.e., the degradation of the sample must be exclusively related to the organic part $\beta$-CD.

The surface morphology of synthesized $\beta-\mathrm{CD}-\mathrm{Fe} / \mathrm{La} /$ $\mathrm{Zn}$ was analyzed using scanning electron microscopy. The images of $\beta$-CD-Fe/La/Zn (Figures $2(a)-2(d)$ ) show fibrous morphology due to presence of cyclodextrin, and the highly agglomerated nanoparticles are clearly visible. In addition, transmission electron microscope provided the information of the particle size of the material. The $\beta$-CD-Fe/La/Zn (Figures 3(a)-3(d)) is nearly spherical and average size is about $20-50 \mathrm{~nm}$. $\beta$-CD-Fe/La/Zn shows metallic particle agglomeration, and the images suggest that the particles well disperse in the matrix of $\beta$-CD and mostly spherical in shape. The Figure 4(a) illustrates the absorption spectrum of $\beta-\mathrm{CD}-\mathrm{Fe} / \mathrm{La} / \mathrm{Zn}$, and Figure 4(b) shows the band gap of the material. The band gap of the $\beta$-CD-Fe/La/Zn nanocomposite is $2.67 \mathrm{eV}$, and therefore, this befalls in a semiconductor material band gap range. Thus, $\beta-\mathrm{CD}-\mathrm{Fe} / \mathrm{La} / \mathrm{Zn}$ has potential to be explored as photocatalyst.

3.2. Heterostructure of $\beta-\mathrm{CD}-\mathrm{Fe} / \mathrm{La} / \mathrm{Zn}$. The band gap for $\mathrm{Fe}_{3} \mathrm{O}_{4}, \mathrm{La}_{2} \mathrm{O}_{3}$, and $\mathrm{ZnO}$ were found to be $2.24 \mathrm{eV}, 2.93$, and 3.23. Whereas, their valance band and conduction values were found to be for $\mathrm{Fe}_{3} \mathrm{O}_{4} \mathrm{VB} 2.40 \mathrm{eV}$ and $\mathrm{CB} 0.16 \mathrm{eV}$, for $\mathrm{La}_{2} \mathrm{O}_{3} \mathrm{VB} 2.24 \mathrm{eV}$ and CB-0.69 eV, and for $\mathrm{ZnO} \mathrm{VB} 2.93 \mathrm{eV}$ and $\mathrm{CB}-0.30 \mathrm{eV}$ as presented in inset Scheme 2. The charge transfer mechanism in the synthesized $\mathrm{Fe}_{3} \mathrm{O}_{4} / \mathrm{La}_{2} \mathrm{O}_{3} / \mathrm{ZnO} @$ cyclodextrin heterojunction was found to follow the dual $\mathrm{Z}$-scheme. Under the light illumination, the electrons from the valance band of the metal oxides get shifted to their 

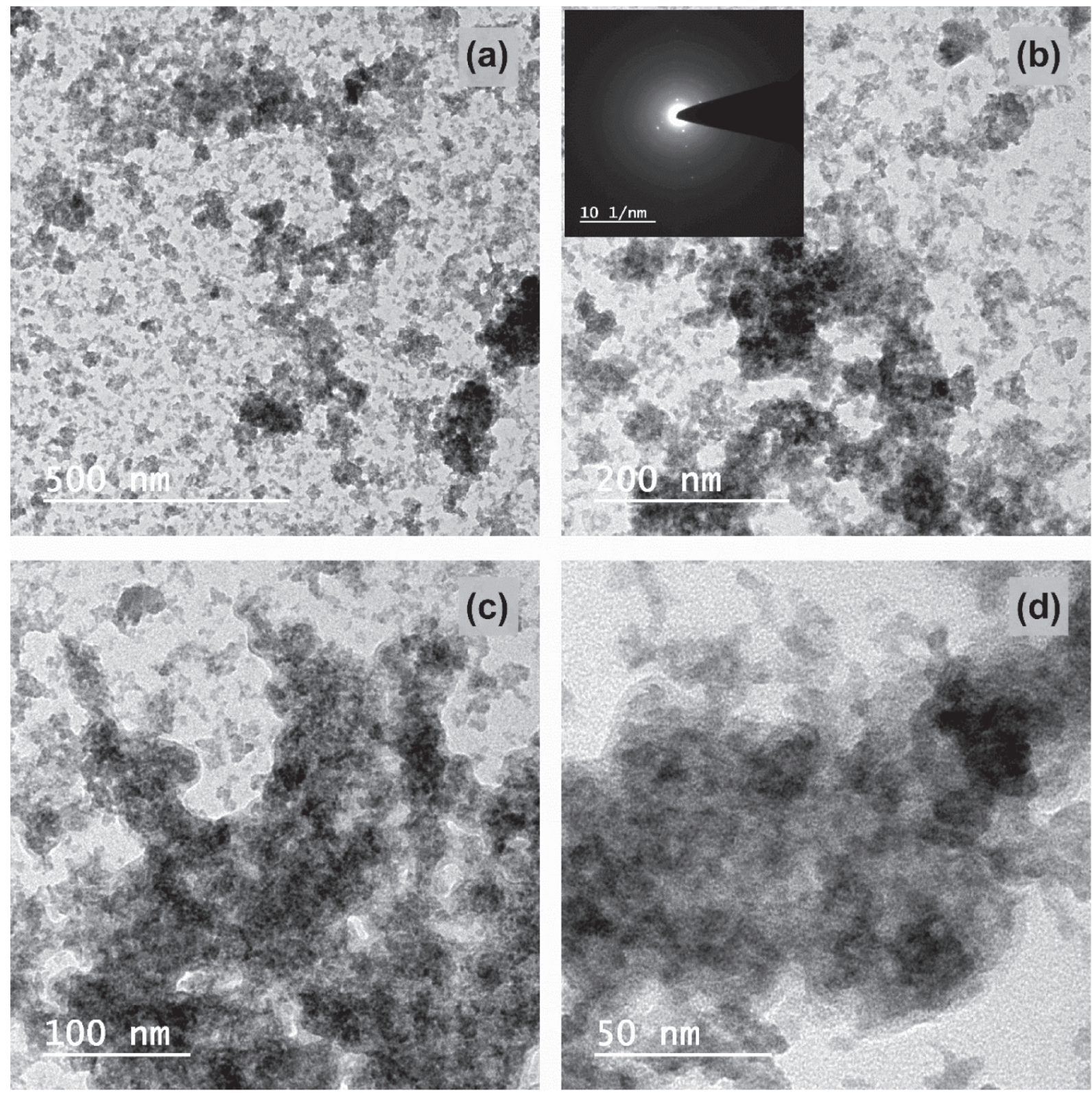

Figure 3: TEM images (a)-(d) for $\beta$-CD-Fe/La/Zn nanocomposite at different scales.

respective conduction band by creating holes there. Since the excitation denotes the unstable state, the electrons from $\mathrm{CB}$ of $\mathrm{Fe}_{3} \mathrm{O}_{4}$ and $\mathrm{ZnO}$ recombine with the holes of $\mathrm{La}_{2} \mathrm{O}_{3}$. As a result, the electrons of $\mathrm{La}_{2} \mathrm{O}_{3}$ with high potential $(-0.69 \mathrm{eV})$ were available for the formation of superoxide radicals. In the same way, the holes of $\mathrm{Fe}_{3} \mathrm{O}_{4}(2.40 \mathrm{eV})$ and $\mathrm{ZnO}$ $(2.93 \mathrm{eV})$ with high potential were free for the generation of hydroxyl radicals (Scheme 2). The simultaneous transfer of the photogenerated charges helped in promoting the separation of charge pairs and thus increased the production and lifetimes of the charge pairs [54].

\section{Applications}

4.1. Remediation of Antibiotics (Amoxicillin). The removal of amoxicillin was studied using the $\beta-\mathrm{CD}-\mathrm{Fe} / \mathrm{La} / \mathrm{Zn}$ under two conditions: (i) equilibrium adsorption (dark) followed by photocatalysis and (ii) simultaneously adsorption/ photocatalysis under sunlight irradiation. The decline in absorption band intensities for the amoxicillin with irradiation time is shown in Figures 5(a)-5(b). It can be clearly seen that decrease in absorbance is more under condition simultaneously adsorption/photocatalysis. Under the first condition, adsorption followed by photocatalysis, only $52 \%$ amoxicillin was adsorbed by $\beta-\mathrm{CD}-\mathrm{Fe} / \mathrm{La} / \mathrm{Zn}$ as Figure 6(a) displays. The complete remediation using the same set of condition indicated a removal of $71 \%$ amoxicillin, which was recorded after $4 \mathrm{~h}$ of remediation. The slight change in the results indicated that $\beta-\mathrm{CD}-\mathrm{Fe} / \mathrm{La} / \mathrm{Zn}$ is a good adsorbent and photocatalytic agent with good removal percentage. Whereas, electrolytic combustion efficiencies of the $\mathrm{PbO}_{2}$ electrode and $\mathrm{Cu}-\mathrm{PbO}_{2}$ electrode for the 


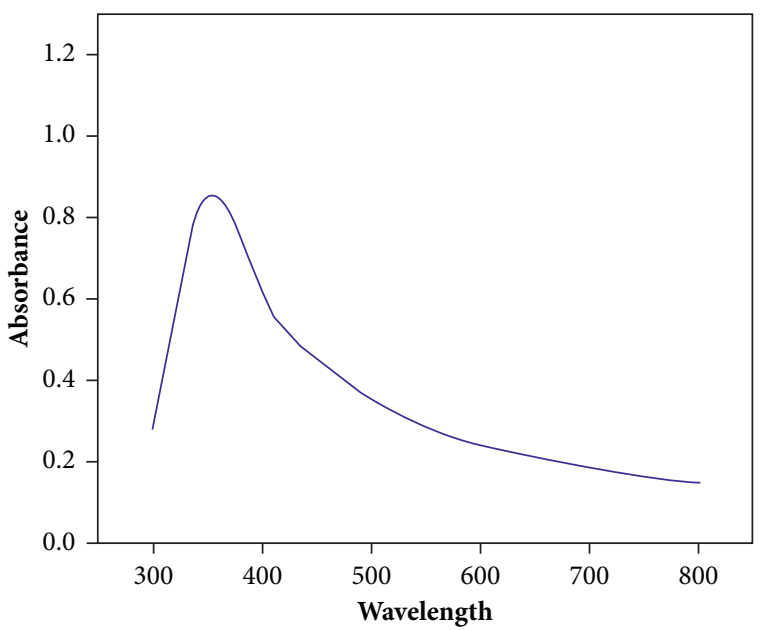

(a)

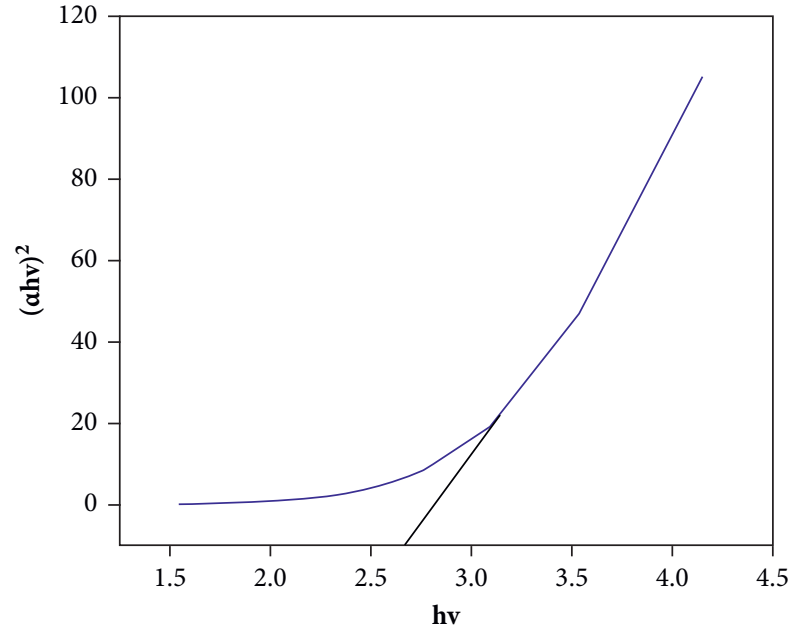

(b)

Figure 4: (a) UV-Vis spectra and (b) Tauc plot of $\beta$-CD-Fe/La/Zn.

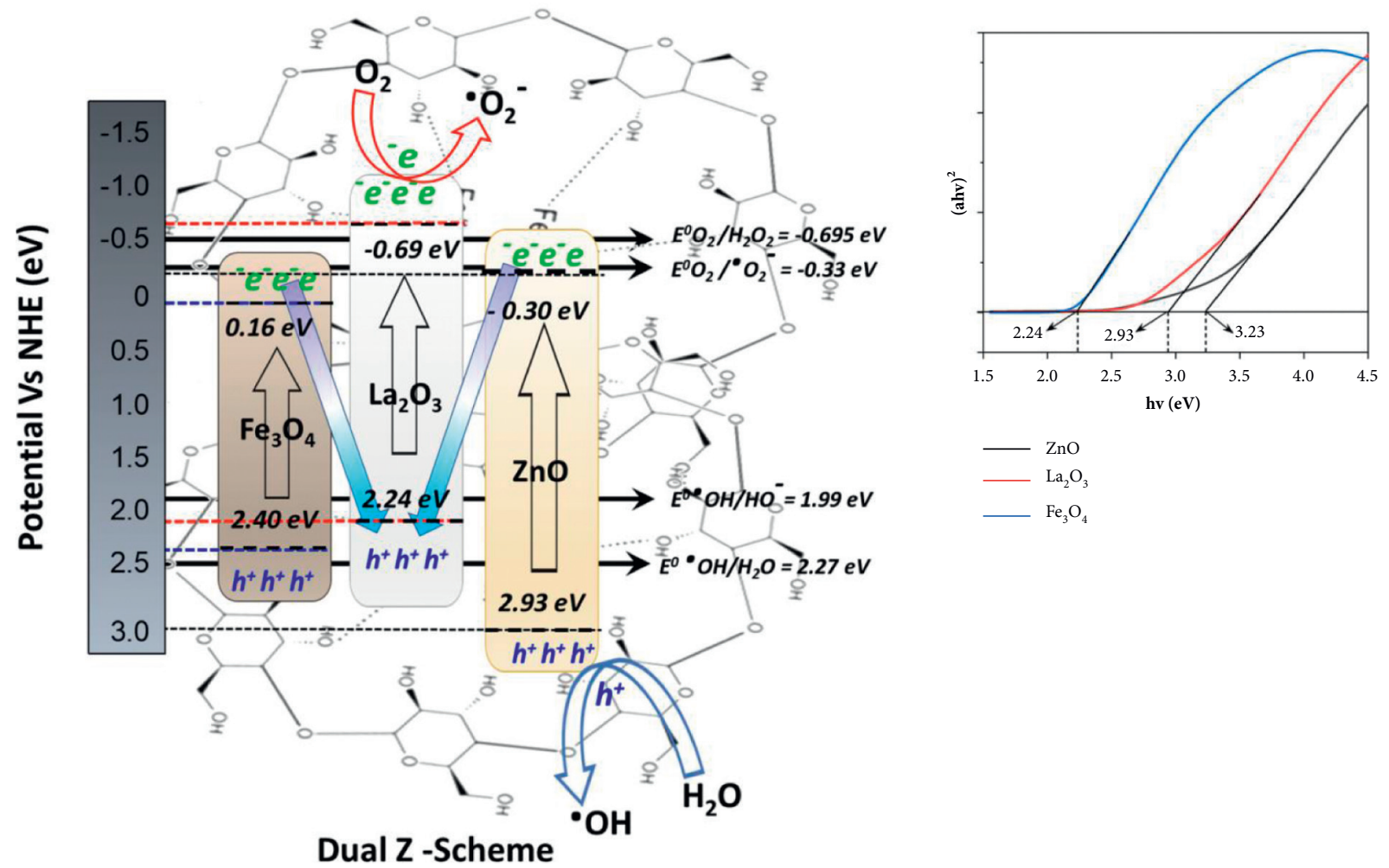

Scheme 2: Heterostructure of $\beta$-CD-Fe/La/Zn; inset band gap for Fe/La/Zn.

degradation reaction of amoxicillin were $65.6 \%$ and $98.4 \%$ [55]. Adsorption and biodegradation in the A/O-MBR system represented the $68 \%$ removal of amoxicillin antibiotic [56]. The natural montmorillonite clay pillared with titanium oxide depicted adsorptive removal of $4.26 \mathrm{mg} / \mathrm{g}$ for amoxicillin [57]. The over photodegrading method has advantages as it is greener using sunlight, and there are no secondary contaminates.
The photodegradation mechanism of amoxicillin under equilibrium adsorption (dark) followed by photocatalysis is the following:

$\beta-\mathrm{CD}-\mathrm{Fe} / \mathrm{La} / \mathrm{Zn}+$ amoxicillin $\longrightarrow \beta-\mathrm{CD}-\mathrm{Fe} / \mathrm{La} /$ Zn-amoxicillin absorbed (in dark)

$\beta$-CD-Fe/La/Zn-amoxicillin absorbed + hv $\longrightarrow \beta-\mathrm{CD}-$ $\mathrm{Fe} / \mathrm{La} / \mathrm{Zn}\left(\mathrm{e}^{-}+\mathrm{h}^{+}\right)$-amoxicillin (sunlight) 


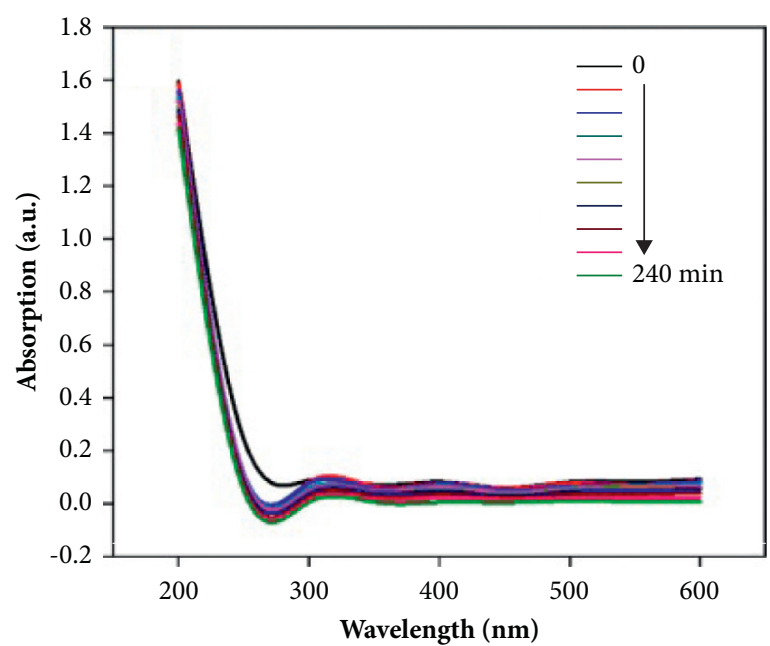

(a)

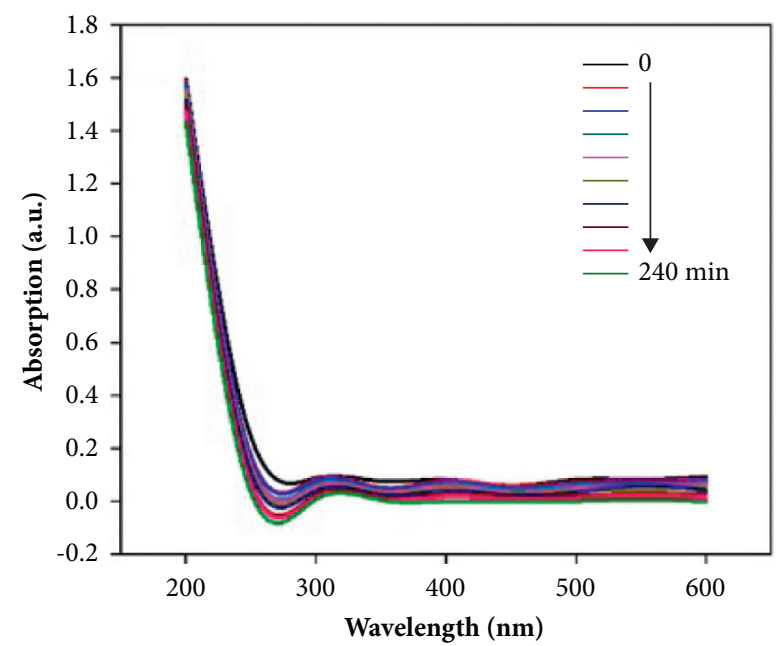

(b)

FIGURE 5: Spectral changes of amoxicillin: (a) adsorption (dark) followed by photocatalysis and (b) simultaneous adsorption/photocatalysis in presence of $\beta-\mathrm{CD}-\mathrm{Fe} / \mathrm{La} / \mathrm{Zn}$.

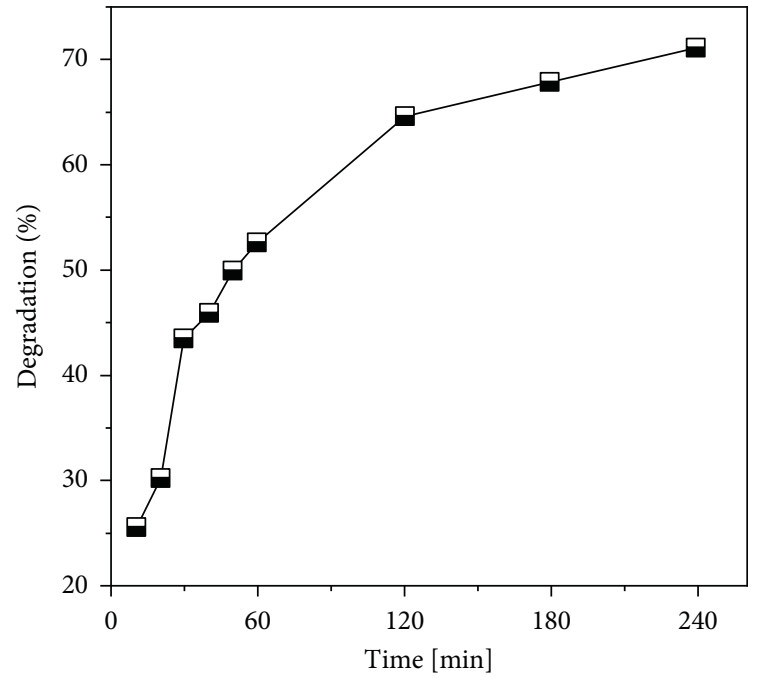

(a)

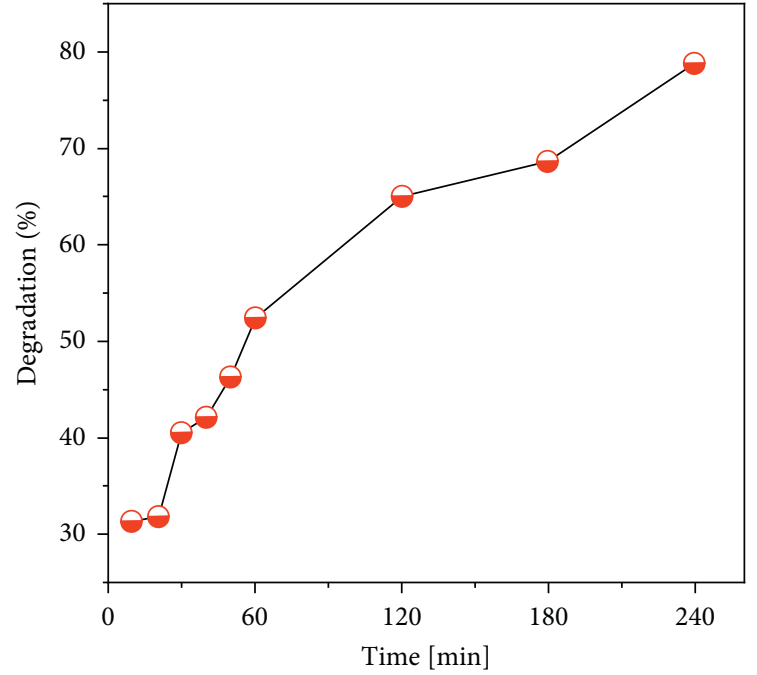

(b)

Figure 6: Continued. 


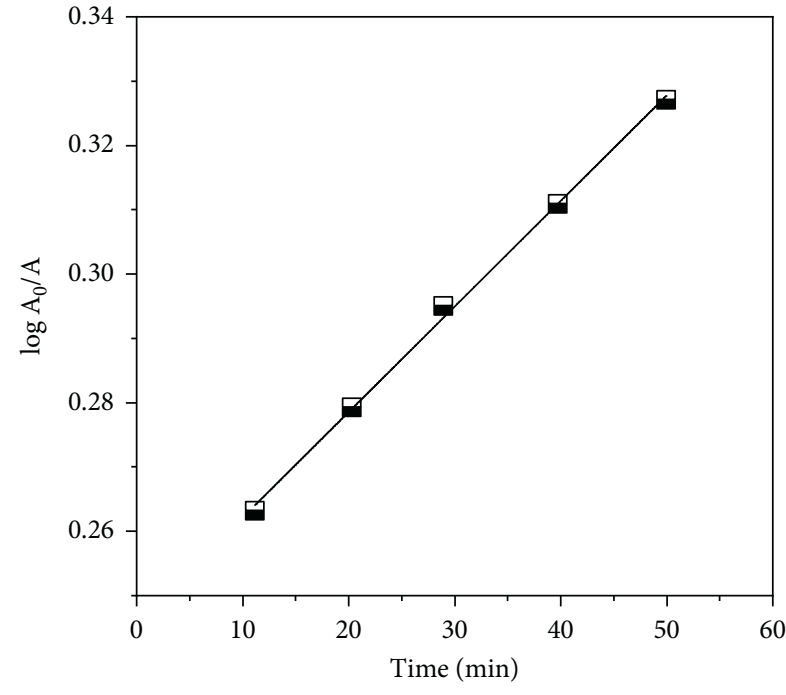

(c)

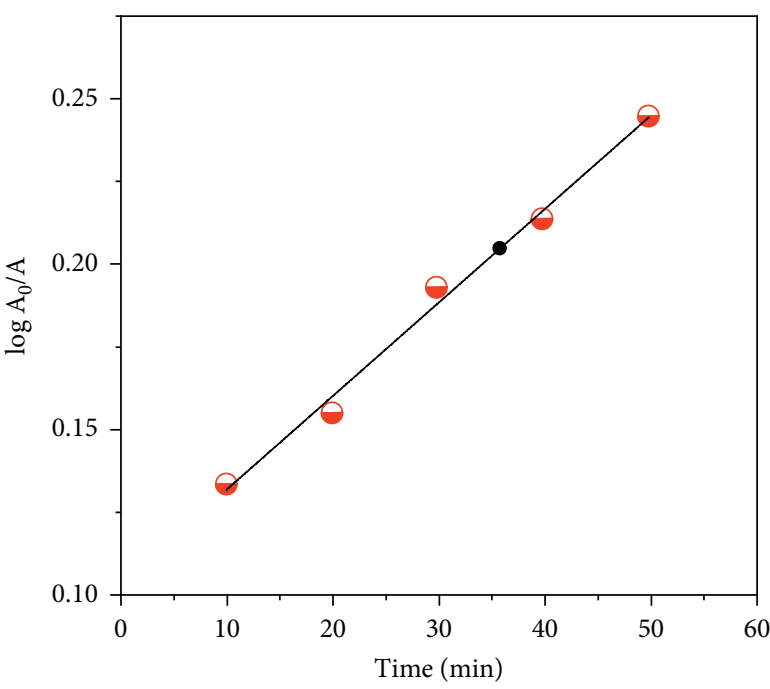

(d)

Figure 6: Percentage removal of amoxicillin: (a) adsorption (dark) followed by photocatalysis and (b) simultaneous adsorption/photocatalysis; pseudo-first-order kinetics for photodegradation of amoxicillin: (c) adsorption (dark) followed by photocatalysis and (d) simultaneous adsorption/photocatalysis in presence of $\beta-\mathrm{CD}-\mathrm{Fe} / \mathrm{La} / \mathrm{Zn}$.

$\cdot \mathrm{OH}+$ amoxicillin $-\beta-\mathrm{CD}-\mathrm{Fe} / \mathrm{La} / \mathrm{Zn} \longrightarrow$ degraded and intermediate product

- $\mathrm{O}_{2}{ }^{-}+$amoxicillin- $\beta$-CD-Fe/La/Zn $\longrightarrow$ degraded and intermediate product

The second set of conditions lead to $78 \%$ of degradation along 4 hours of photoirradiation, as shown in Figure 6(b). Hence, $\beta$-CD-Fe/La/Zn seems a good photocatalytic agent. On the other hand, kinetics for amoxicillin degradation express a linear correlation as it can be observed in Figure 6(c) [17]. The value of rate constant $(k)$ was $0.00156 \mathrm{~min}^{-1}$ and with a correlation coefficient $\left(R^{2}\right)$ of 0.99769 .

The simultaneous adsorption/photocatalysis of amoxicillin onto $\beta$-CD-Fe/La/Zn comprises the adsorption of amoxicillin onto it and the generation of electron-hole pair from $\beta-\mathrm{CD}-\mathrm{Fe} / \mathrm{La} / \mathrm{Zn}$ on the absorption of visible light. Excited particle generates hydroxyl and superoxide radicals. Then, these free radicals upset the conjugation in the adsorbed amoxicillin molecules and consequently destroy the amoxicillin molecules. The degraded amoxicillin products left the surface of $\beta$-CD-Fe/La/Zn free for additional photocatalysis. The mechanism of amoxicillin photodegradation in simultaneous adsorption/photocatalysis was the following:

$\beta$-CD-Fe/La/Zn + amoxicillin $\longrightarrow$ amoxicillin adsorbed (in sunlight) + hv

$\beta$-CD-Fe/La/Zn $\left(\mathrm{h}^{+}\right)$-amoxicillin $+\mathrm{H}_{2} \mathrm{O} \longrightarrow \beta$-CD-Fe/ $\mathrm{La} / \mathrm{Zn}(\bullet \mathrm{OH})-$ amoxicillin $+\mathrm{H}^{+}$

$\beta$-CD-Fe/La/Zn $\quad\left(\mathrm{h}^{+}\right)$-amoxicillin absorbed $+\mathrm{OH}$ $\beta$-CD-Fe/La/Zn/ $/ \bullet \mathrm{OH})-$ amoxicillin

$\beta$-CD-Fe/La/Zn ( $\left.\mathrm{e}^{-}\right)$-amoxicillin absorbed $+\mathrm{O}_{2} \longrightarrow$ $\beta$-CD-Fe/La/Zn $\left(\bullet \mathrm{O}_{2}{ }^{-}\right)$-amoxicillin
- $\mathrm{OH}+$ amoxicillin $-\beta-\mathrm{CD}-\mathrm{Fe} / \mathrm{La} / \mathrm{Zn} \longrightarrow$ intermediate product $\longrightarrow$ degrade product + free $\beta-\mathrm{CD}-\mathrm{Fe} / \mathrm{La} / \mathrm{Zn}$ for reuse

- $\mathrm{O}_{2}{ }^{-}+$amoxicillin $-\beta-\mathrm{CD}-\mathrm{Fe} / \mathrm{La} / \mathrm{Zn} \longrightarrow$ intermediate product $\longrightarrow$ degraded product + free $\beta-\mathrm{CD}-\mathrm{Fe} / \mathrm{La} / \mathrm{Zn}$ for reuse

The amoxicillin degradation kinetics show a linear correlation in Figure 6(d), which was fitted through pseudofirst-order kinetics [17]. The value of rate constant $(k)$ was 0.00284 and 0.99098 was the correlation coefficient $\left(R^{2}\right)$.

The photocatalytic study of amoxicillin degradation in presence of $\beta-\mathrm{CD}-\mathrm{Fe} / \mathrm{La} / \mathrm{Zn}$ displays that the trimetallic nanocomposite is a better agent for the amoxicillin photoremediation. The results can be supported with band gap studies as its band gap value is $2.67 \mathrm{eV}$. This low band gap value of $\beta$-CD-Fe/La/Zn helps to generate an electron-hole pair, leading to a higher photocatalytic degradation. In addition, the great number of $-\mathrm{OH}$ groups in $\beta-\mathrm{CD}$ is the responsible of the adsorption of amoxicillin onto the surface. This adsorbed amoxicillin is further effectively prone to radicals' attack than the suspended one. The transferred electron leads to the formation of adsorbed amoxicillin radical cation, which further yields oxygen radical anion and brings the degradation of amoxicillin by interruption of the conjugation. In Figure 7(a), the scavengers effect, it is clearly detected that addition of TEMPOL and tert-butanol inhibits the degradation rate abruptly, from $78 \%$ to 26 and $14 \%$, respectively, which indicate that $\bullet \mathrm{O} 2-$ and $\bullet \mathrm{OH}$ are the main active species participating in photodegradation. The degradation rate inhibition follows the order: $\mathrm{AgNO}_{3}>$ EDTA $>$ TEMPOL $>$ tert-butanol. The analysis of chemical oxygen demand depicts (Figure 7(b)) gradual fall to $21 \%$ in 240 minutes and hence confirms the degradation of amoxicillin. 


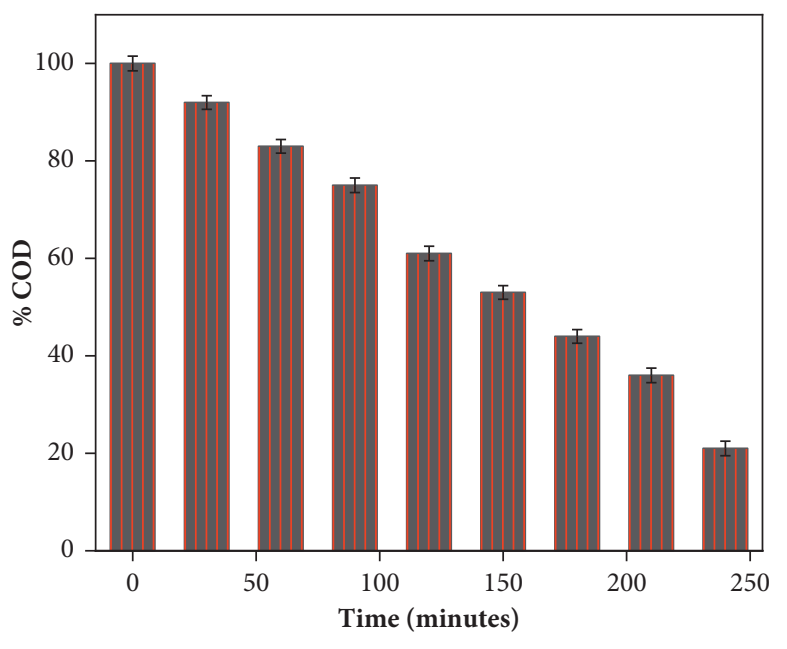

(a)

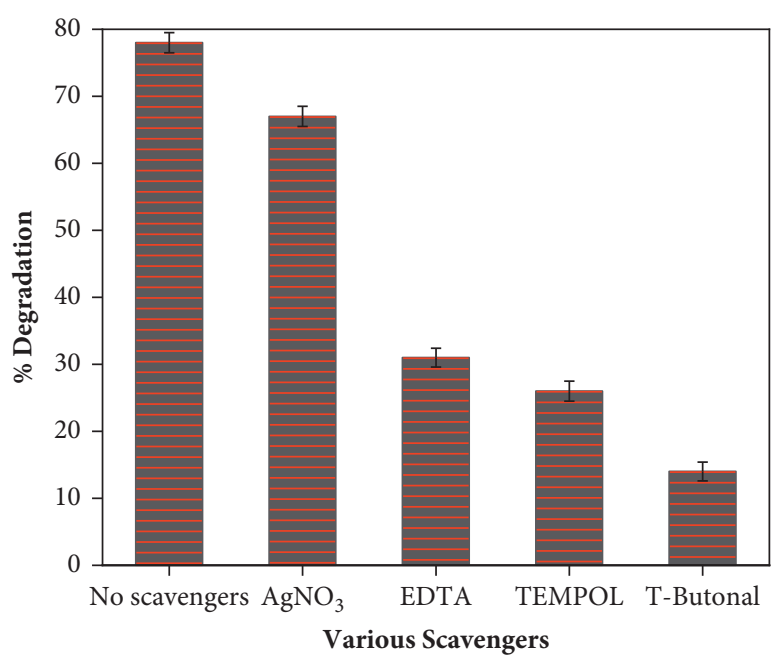

(b)

Figure 7: (a) Percent COD and the (b) effect of scavengers for photocatalytic degradation of amoxicillin using $\beta$-CD-Fe/La/Zn.

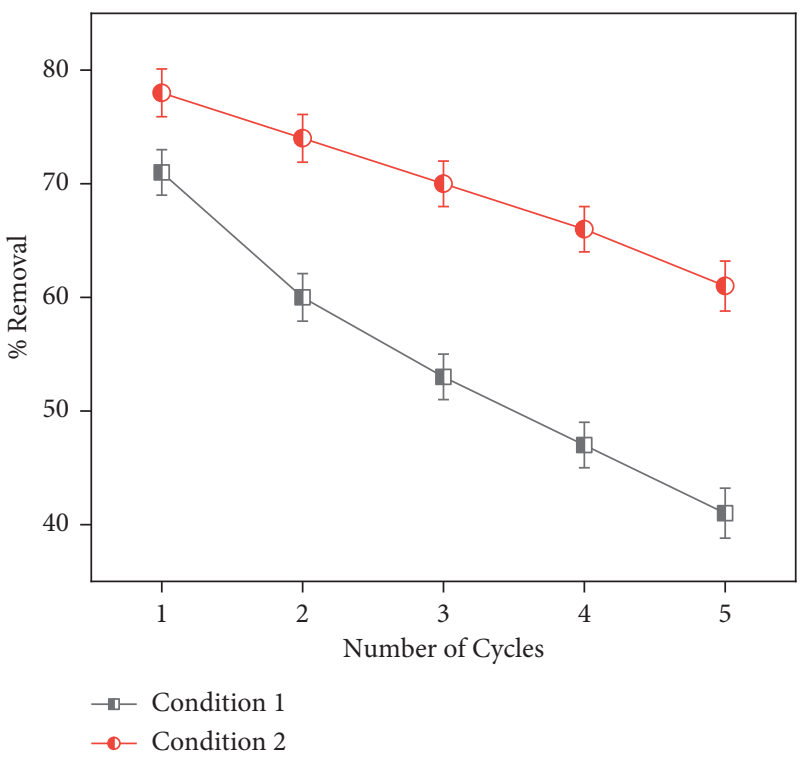

FIGURE 8: Reusability study for removal of amoxicillin using $\beta$-CD-Fe/La/Zn.

The adsorption of pollutants onto the catalyst surface can enhance the photodegradation [58-60]. The hydroxyl groups and primary amino groups on the surface of amoxicillin provide a large number of adsorption sites for interactions. Reusability studies show that $\beta-\mathrm{CD}-\mathrm{Fe} / \mathrm{La} / \mathrm{Zn}$ was more efficient in simultaneous adsorption/photocatalysis under sunlight as after five cycles of removal, it still retains $61 \%$ removal efficiency, whereas in equilibrium adsorption (dark) followed by photocatalysis condition, there was appreciable loss, and only it showed removal efficiency of $41 \%$ after 5 cycles (Figure 8 ). This may be as the adsorption of amoxicillin under dark conditions degrades the photoactive sites responsible for degradation.

\subsection{Exploring Electrocatalytic Nature of Fe/La/Zn@ $\beta-C D$ for} Esterification Reactions. The esterification reactions are reasonably slow and require activation through high temperature or using a catalyst for reaching the equilibrium conversion in a practical amount. In addition, esterification is reversible and possesses low equilibrium constants.

The reaction requisites to be enforced by confiscating water produced or working with an excess of one of the two reactants (acid or alcohol) for getting higher yields of the esters. In this context, the existence of water during the esterification could reduce the product yield. The effect of adding a cosolvent raises the reaction rate and product yield. Consequently, solvents such as toluene was used for reaction, so the water formed during the reaction could be removed. Furthermore, some reactions were optimized using ethyl acetate.

The reactions of esterification using different alcohols are displayed in Scheme 3. The conditions were selected in order 

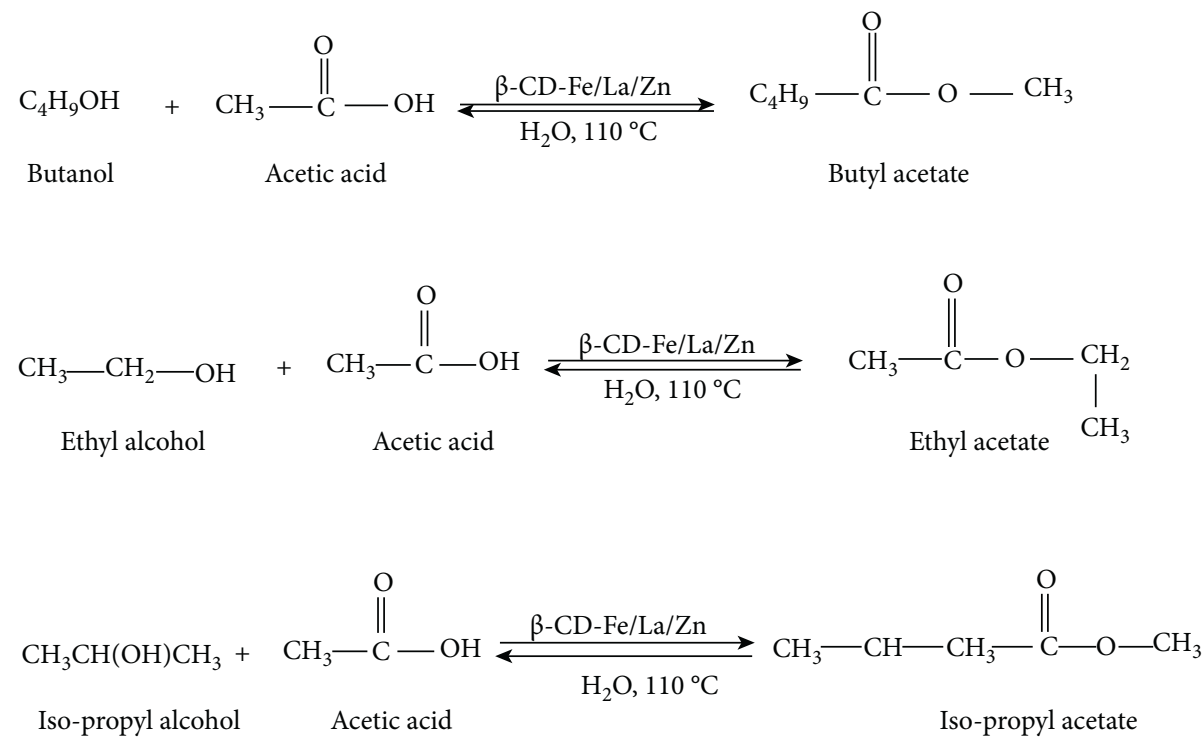

Scheme 3: Esterification of acetic acid with butanol, ethyl alcohol, and iso propyl alcohol using $\beta$-CD-Fe/La/Zn as the catalyst.

Table 1: Percentage of yield for the different esters.

\begin{tabular}{|c|c|c|c|c|}
\hline Case & $-\mathrm{OH}: \mathrm{CH}_{3} \mathrm{COOH}, \mathrm{T}$ & Ester formed & Amount of catalyst & $\%$ yield \\
\hline 1 & Ethanol, $110^{\circ} \mathrm{C}$ & Ethyl acetate & $10 \mathrm{mg}$ & 84 \\
\hline 2 & Ethanol, $110^{\circ} \mathrm{C}$ & Ethyl acetate & $20 \mathrm{mg}$ & 88 \\
\hline 3 & Isopropyl alcohol, $110^{\circ} \mathrm{C}$ & Isopropyl acetate & $10 \mathrm{mg}$ & 80 \\
\hline 4 & Isopropyl alcohol, $110^{\circ} \mathrm{C}$ & Isopropyl acetate & $20 \mathrm{mg}$ & 92 \\
\hline 5 & Butanol $110^{\circ} \mathrm{C}$ & Butyl acetate & $10 \mathrm{mg}$ & 80 \\
\hline 6 & Butanol $110^{\circ} \mathrm{C}$ & Butyl acetate & $20 \mathrm{mg}$ & 80 \\
\hline
\end{tabular}

to obtain the maximum yield of ester, and these were using $20 \mathrm{mg}$ of $\beta$-CD-Fe/La/Zn as catalyst, a mole ratio $2: 1$ (acid: alcohol), and a time of 2.5 hours. Table 1 provides the yields of the diverse esters obtained in this study. First, the higher yield obtained are when ethanol and isopropyl alcohol are involved.

In literature, $\mathrm{H}_{2} \mathrm{SO}_{4}$ was used as the catalyst during the procedure, which requires $5 \mathrm{~mL}$ of acid as the catalyst for preparing the esters. The acid will be diluted by eliminated water produced during the conversion, and therefore, the catalytic effect will be reduced. Hence, a higher amount of acid will be required for getting a high yield.

The data show that a maximum of yield, $92 \%$, is reached for the isopropyl acetate using $20 \mathrm{mg}$ of $\beta$-CD-Fe/La/Zn catalyst. On the other hand, the maximum yield for butyl acetate was $80 \%$ and $88 \%$ for ethyl acetate using the same amount of $\beta$-CD-Fe/La/Zn catalyst. Thus, these results show that $\beta-\mathrm{CD}-\mathrm{Fe} / \mathrm{La} / \mathrm{Zn}$ material is potentially useful for esterification reactions.

\section{Conclusions}

The $\beta$-CD-Fe/La/Zn TNCs composite was fabricated using the microemulsion technique, and the structure was confirmed by scanning electron microscopy (SEM), X-ray diffractometer (XRD), Fourier transform infrared spectroscopy (FTIR), and transmission electron microscopy (TEM). The new composite exhibits good properties as photocatalyst for photodegradation of amoxicillin under the diverse conditions studied. The adsorption/photocatalysis lead to $78 \%$ of degradation of amoxicillin. Reusability studies display that $\beta$-CD-Fe/La/Zn was more effective in simultaneous adsorption/photocatalysis; even as after five cycles of exclusion, it still retains $61 \%$ removal efficacy. Hence, this new material seems an excellent agent for removal some antibiotics such as amoxicillin. $\beta$-CD$\mathrm{Fe} / \mathrm{La} / \mathrm{Zn}$ TNCs is also a promising catalyst for esterification reactions, such as the higher reaction yields indicated. In this context, the esterification of acetic acid with ethyl, isopropyl, and butyl alcohol showed that ethyl, isopropyl, and butyl alcohol reached a maximum yield of $88 \%, 80 \%$, and $92 \%$. Thus, a high number of applications can be attained using this promising $\beta-\mathrm{CD}-\mathrm{Fe} / \mathrm{La} / \mathrm{Zn}$ material.

\section{Data Availability}

No data were used to support this study.

\section{Conflicts of Interest}

The authors declare that they have no conflicts of interest. 


\section{Acknowledgments}

The authors are grateful to the Researchers Supporting Project number (RSP-2021/8), King Saud University, Riyadh, Saudi Arabia, for the financial support. The authors are also thankful to the Shenzhen University, China, and Shoolini University, India, for providing the research facilities. The financial support from China Postdoctoral Science Foundation Grant (2018M643168) is greatly acknowledged.

\section{References}

[1] Z. P. Xu, Q. H. Zeng, G. Q. Lu, and A. B. Yu, "Inorganic nanoparticles as carriers for efficient cellular delivery," Chemical Engineering Science, vol. 61, no. 3, pp. 1027-1040, 2006.

[2] C. Xu, J. Xie, D. Ho et al., "Au-Fe3O4 dumbbell nanoparticles as dual-functional probes," Angewandte Chemie International Edition, vol. 47, no. 1, pp. 173-176, 2008.

[3] C. Xu, B. Wang, and S. Sun, "Dumbbell-like Au-Fe3O4 nanoparticles for target-specific platin delivery," Journal of the American Chemical Society, vol. 131, no. 12, pp. 4216-4217, 2009.

[4] G. Sharma, A. Kumar, S. Sharma et al., "Novel development of nanoparticles to bimetallic nanoparticles and their composites: a review," Journal of King Saud University Science, vol. 31, no. 2, pp. 257-269, 2019.

[5] G. Sharma, D. Kumar, A. Kumar et al., "Revolution from monometallic to trimetallic nanoparticle composites, various synthesis methods and their applications: a review," Materials Science and Engineering: C, vol. 71, pp. 1216-1230, 2017.

[6] Z. Li, G. Liu, Q. Su, C. Lv, X. Jin, and X. Wen, "UV-induced photodegradation of naproxen using a nano $\gamma$-FeOOH composite: degradation kinetics and photocatalytic mechanism," Frontiers in Chemistry, vol. 7847 pages, 2019.

[7] R. Koutavarapu, B. Babu, C. V. Reddy et al., " $\mathrm{ZnO}$ nanosheetsdecorated Bi2WO6 nanolayers as efficient photocatalysts for the removal of toxic environmental pollutants and photoelectrochemical solar water oxidation," Journal of Environmental Management, vol. 265, Article ID 110504, 2020.

[8] Z. Cheng, Q. Wu, J. Li, and Q. Zhu, "Effects of promoters and preparation procedures on reforming of methane with carbon dioxide over Ni/Al2O3 catalyst," Catalysis Today, vol. 30, no. 1-3, pp. 147-155, 1996.

[9] H. Provendier, C. Petit, C. Estournès, S. Libs, and A. Kiennemann, "Stabilisation of active nickel catalysts in partial oxidation of methane to synthesis gas by iron addition," Applied Catalysis A: General, vol. 180, no. 1-2, pp. 163-173, 1999.

[10] C. Bernardo, "Carbon deposition and methane steam reforming on silica-supported Ni\$z.sbnd; Cu catalysts," Journal of Catalysis, vol. 96, no. 2, pp. 517-534, 1985.

[11] X. Chen, Z. Cai, X. Chen, and M. Oyama, "Green synthesis of graphene-PtPd alloy nanoparticles with high electrocatalytic performance for ethanol oxidation," Journal of Materials Chemistry, vol. 2, no. 2, pp. 315-320, 2014.

[12] G. D. Wright, "Resisting resistance: new chemical strategies for battling superbugs," Chemistry \& Biology, vol. 7, no. 6, pp. R127-R132, 2000.

[13] G. Wright, "Bacterial resistance to antibiotics: enzymatic degradation and modification," Advanced Drug Delivery Reviews, vol. 57, no. 10, pp. 1451-1470, 2005.
[14] A. Fakhri, V. K. Gupta, H. Rabizadeh, S. Agarwal, N. Sadeghi, and S. Tahami, "Preparation and characterization of WS2 decorated and immobilized on chitosan and polycaprolactone as biodegradable polymers nanofibers: photocatalysis study and antibiotic-conjugated for antibacterial evaluation," International Journal of Biological Macromolecules, vol. 120, pp. 1789-1793, 2018.

[15] M. Rai, A. Yadav, and A. Gade, "Silver nanoparticles as a new generation of antimicrobials," Biotechnology Advances, vol. 27, no. 1, pp. 76-83, 2009.

[16] I. Sondi and B. Salopek-Sondi, "Silver nanoparticles as antimicrobial agent: a case study on E. coli as a model for Gramnegative bacteria," Journal of Colloid and Interface Science, vol. 275, no. 1, pp. 177-182, 2004.

[17] A. V. Rupa, D. Manikandan, D. Divakar, and T. Sivakumar, "Effect of deposition of $\mathrm{Ag}$ on $\mathrm{TiO} 2$ nanoparticles on the photodegradation of Reactive Yellow-17," Journal of Hazardous Materials, vol. 147, no. 3, pp. 906-913, 2007.

[18] C. Wang, C. Xu, H. Zeng, and S. Sun, "Recent progress in syntheses and applications of dumbbell-like nanoparticles," Advanced Materials, vol. 21, no. 30, pp. 3045-3052, 2009.

[19] F. Zhang, G. B. Braun, Y. Shi et al., "Fabrication of Ag@SiO2@ Y2O3:Er nanostructures for bioimaging: tuning of the upconversion fluorescence with silver nanoparticles," Journal of the American Chemical Society, vol. 132, no. 9, pp. 2850-2851, 2010.

[20] F. Martinez-Gutierrez, P. L. Olive, A. Banuelos et al., "Synthesis, characterization, and evaluation of antimicrobial and cytotoxic effect of silver and titanium nanoparticles," Nanomedicine: Nanotechnology, Biology and Medicine, vol. 6, no. 5, pp. 681-688, 2010.

[21] D. R. Paul and L. M. Robeson, "Polymer nanotechnology: nanocomposites," Polymer, vol. 49, no. 15, pp. 3187-3204, 2008.

[22] S. Yu, J. Wang, and J. Cui, "Preparation of a novel chitosanbased magnetic adsorbent CTS@SnO2@Fe3O4 for effective treatment of dye wastewater," International Journal of Biological Macromolecules, vol. 156, pp. 1474-1482, 2020.

[23] T. S. Koseoglu, E. Kir, S. P. Ozkorucuklu, and E. Karamızrak, "Preparation and characterization of P2FAn/PVDF composite cation-exchange membranes for the removal of $\mathrm{Cr}$ (III) and $\mathrm{Cu}(\mathrm{II})$ by Donnan dialysis," Reactive and Functional Polymers, vol. 70, no. 11, pp. 900-907, 2010.

[24] Q. Zhao, J. Wang, Z. Li et al., "Heterostructured graphiticcarbon-nitride-nanosheets/copper(I) oxide composite as an enhanced visible light photocatalyst for decomposition of tetracycline antibiotics," Separation and Purification Technology, vol. 250, Article ID 117238, 2020.

[25] N. P. Singh, V. K. Gupta, and A. P. Singh, "Graphene and carbon nanotube reinforced epoxy nanocomposites: a review," Polymer, vol. 180, Article ID 121724, 2019.

[26] X. Xu, G. Liu, C. Randorn, and J. T. S. Irvine, "g-C3N4 coated $\mathrm{SrTiO} 3$ as an efficient photocatalyst for $\mathrm{H} 2$ production in aqueous solution under visible light irradiation," International Journal of Hydrogen Energy, vol. 36, no. 21, pp. 13501-13507, 2011.

[27] G. Sharma, D. D. Dionysiou, S. Sharma et al., "Highly efficient Sr/Ce/activated carbon bimetallic nanocomposite for photoinduced degradation of rhodamine B," Catalysis Today, vol. 335, pp. 437-451, 2019.

[28] M. Naushad, Z. A. Alothman, M. R. Awual, M. M. Alam, and G. E. Eldesoky, "Adsorption kinetics, isotherms, and thermodynamic studies for the adsorption of $\mathrm{Pb} 2+$ and $\mathrm{Hg} 2+$ 
metal ions from aqueous medium using Ti(IV) iodovanadate cation exchanger," Ionics, vol. 21, no. 8, pp. 2237-2245, 2015.

[29] G. Sharma, A. Kumar, S. Sharma et al., "Fe3O4/ZnO/Si3N4 nanocomposite based photocatalyst for the degradation of dyes from aqueous solution," Materials Letters, vol. 278, Article ID 128359, 2020.

[30] G. Sharma, B. Thakur, A. Kumar, S. Sharma, M. Naushad, and F. J. Stadler, "Atrazine removal using chitin-cl-poly(acrylamide-co-itaconic acid) nanohydrogel: isotherms and $\mathrm{pH}$ responsive nature," Carbohydrate Polymers, vol. 241, Article ID 116258, 2020.

[31] F. Liu, C. Chen, and J. Qian, "Film-like bacterial cellulose/ cyclodextrin oligomer composites with controllable structure for the removal of various persistent organic pollutants from water," Journal of Hazardous Materials, vol. 405, Article ID 124122, 2021.

[32] D. Thakre, S. Jagtap, A. Bansiwal, N. Labhsetwar, and S. Rayalu, "Synthesis of La-incorporated chitosan beads for fluoride removal from water," Journal of Fluorine Chemistry, vol. 131, no. 3, pp. 373-377, 2010.

[33] G. Sharma, A. Kumar, M. Naushad et al., "Photoremediation of toxic dye from aqueous environment using monometallic and bimetallic quantum dots based nanocomposites," Journal of Cleaner Production, vol. 172, pp. 2919-2930, 2018.

[34] L. A. Wali, A. M. Alwan, A. B. Dheyab, and D. A. Hashim, "Excellent fabrication of Pd-Ag NPs/PSi photocatalyst based on bimetallic nanoparticles for improving methylene blue photocatalytic degradation," Optik, vol. 179, pp. 708-717, 2019.

[35] E. Brillas, I. Sirés, and M. A. Oturan, "Electro-Fenton process and related electrochemical technologies based on Fenton's reaction chemistry," Chemical Reviews, vol. 109, no. 12, pp. 6570-6631, 2009.

[36] G. Sharma, M. Naushad, A. a. H. Al-Muhtaseb et al., "Fabrication and characterization of chitosan-crosslinked-poly(alginic acid) nanohydrogel for adsorptive removal of $\mathrm{Cr}(\mathrm{VI})$ metal ion from aqueous medium," International Journal of Biological Macromolecules, vol. 95, pp. 484-493, 2017.

[37] G. Sharma, M. Naushad, A. Kumar et al., "Efficient removal of coomassie brilliant blue R-250 dye using starch/poly(alginic acid-cl-acrylamide) nanohydrogel," Process Safety and Environmental Protection, vol. 109, pp. 301-310, 2017.

[38] A. Mittal, M. Naushad, G. Sharma, Z. A. Alothman, S. M. Wabaidur, and M. Alam, "Fabrication of MWCNTs/ ThO2 nanocomposite and its adsorption behavior for the removal of $\mathrm{Pb}(\mathrm{II})$ metal from aqueous medium," Desalination and Water Treatment, vol. 57, no. 46, pp. 21863-21869, 2016.

[39] A. A. El-Bindary, A. Z. El-Sonbati, A. A. Al-Sarawy, K. S. Mohamed, and M. A. Farid, "Removal of hazardous azopyrazole dye from an aqueous solution using rice straw as a waste adsorbent: kinetic, equilibrium and thermodynamic studies," Spectrochimica Acta Part A: Molecular and Biomolecular Spectroscopy, vol. 136, pp. 1842-1849, 2015.

[40] Q. Liu, Y. Zhou, J. Lu, and Y. Zhou, "Novel cyclodextrinbased adsorbents for removing pollutants from wastewater: a critical review," Chemosphere, vol. 241, Article ID 125043, 2020.

[41] N. Morin-Crini, P. Winterton, S. Fourmentin, L. D. Wilson, É. Fenyvesi, and G. Crini, "Water-insoluble $\beta$-cyclodextrinepichlorohydrin polymers for removal of pollutants from aqueous solutions by sorption processes using batch studies: a review of inclusion mechanisms," Progress in Polymer Science, vol. 78, pp. 1-23, 2018.
[42] E. M. M. Del Valle, "Cyclodextrins and their uses: a review," Process Biochemistry, vol. 39, no. 9, pp. 1033-1046, 2004.

[43] C. R. Dass, W. Jessup, and A.-I. Apolipoprotein, "Cyclodextrins and liposomes as potential drugs for the reversal of atherosclerosis. A review," Journal of Pharmacy and Pharmacology, vol. 52, pp. 731-761, 2000.

[44] G. Sharma, M. Naushad, A. Kumar, S. Devi, and M. R. Khan, "Lanthanum/Cadmium/Polyaniline bimetallic nanocomposite for the photodegradation of organic pollutant," Iranian Polymer Journal (English Edition), vol. 24, no. 12, pp. 1003-1013, 2015.

[45] A. Kumar, G. Sharma, M. Naushad et al., "Visible photodegradation of ibuprofen and 2,4-D in simulated waste water using sustainable metal free-hybrids based on carbon nitride and biochar," Journal of Environmental Management, vol. 231, pp. 1164-1175, 2019.

[46] M. A. Subhan, T. Ahmed, P. Sarker et al., "Structural, luminescence and photophysical properties of novel trimetallic nanocomposite $\mathrm{CeO} 2 \cdot \mathrm{ZnO} \cdot \mathrm{ZnAl} 2 \mathrm{O} 4$," Journal of Luminescence, vol. 148, pp. 98-102, 2014.

[47] G. Sharma, M. Naushad, D. Pathania, A. Mittal, and G. E. Eldesoky, "Modification ofHibiscus cannabinusfiber by graft copolymerization: application for dye removal," Desalination and Water Treatment, vol. 54, no. 11, pp. 3114-3121, 2015.

[48] M. Naushad, G. Sharma, and Z. A. Alothman, "Photodegradation of toxic dye using Gum Arabic-crosslinkedpoly(acrylamide)/ $\mathrm{Ni}(\mathrm{OH}) 2 / \mathrm{FeOOH}$ nanocomposites hydrogel," Journal of Cleaner Production, vol. 241, Article ID 118263, 2019.

[49] G. Sharma, A. Kumar, S. Sharma et al., "Fabrication and characterization of novel Fe0@Guar gum-crosslinked-soya lecithin nanocomposite hydrogel for photocatalytic degradation of methyl violet dye," Separation and Purification Technology, vol. 211, pp. 895-908, 2019.

[50] S. R. Lakhotia, M. Mukhopadhyay, and P. Kumari, "Iron oxide $(\mathrm{FeO})$ nanoparticles embedded thin-film nanocomposite nanofiltration (NF) membrane for water treatment," Separation and Purification Technology, vol. 211, pp. 98-107, 2019.

[51] M. R. Buck, J. F. Bondi, and R. E. Schaak, "A total-synthesis framework for the construction of high-order colloidal hybrid nanoparticles," Nature Chemistry, vol. 4, no. 1, pp. 37-44, 2011.

[52] R. Costi, A. E. Saunders, and U. Banin, "Colloidal hybrid nanostructures: a new type of functional materials," Angewandte Chemie International Edition, vol. 49, no. 29, pp. 4878-4897, 2010.

[53] B. Baruah, L. Downer, and D. Agyeman, "Fabric-based composite materials containing $\mathrm{ZnO}-\mathrm{NRs}$ and $\mathrm{ZnO}$-NRsAuNPs and their application in photocatalysis," Materials Chemistry and Physics, vol. 231, pp. 252-259, 2019.

[54] J. Kang, C. Jin, Z. Li, M. Wang, Z. Chen, and Y. Wang, "Dual Z-scheme MoS2/g-C3N4/Bi24O31Cl10 ternary heterojunction photocatalysts for enhanced visible-light photodegradation of antibiotic," Journal of Alloys and Compounds, vol. 825, Article ID 153975, 2020.

[55] J. Hu, X. Bian, Y. Xia, M. Weng, W. Zhou, and Q. Dai, "Application of response surface methodology in electrochemical degradation of amoxicillin with $\mathrm{Cu}-\mathrm{PbO} 2$ electrode: optimization and mechanism," Separation and Purification Technology, vol. 250, Article ID 117109, 2020.

[56] M. E. Matsubara, K. Helwig, C. Hunter, J. Roberts, E. L. Subtil, and L. H. G. Coelho, "Amoxicillin removal by pre-denitrification membrane bioreactor (A/O-MBR): performance evaluation, degradation by-products, and antibiotic resistant 
bacteria," Ecotoxicology and Environmental Safety, vol. 192, Article ID 110258, 2020.

[57] M. Chauhan, V. K. Saini, and S. Suthar, "Ti-pillared montmorillonite clay for adsorptive removal of amoxicillin, imipramine, diclofenac-sodium, and paracetamol from water," Journal of Hazardous Materials, vol. 399, Article ID 122832, 2020.

[58] C. H. Nguyen and R.-S. Juang, "Efficient removal of cationic dyes from water by a combined adsorption-photocatalysis process using platinum-doped titanate nanomaterials," Journal of the Taiwan Institute of Chemical Engineers, vol. 99, pp. 166-179, 2019.

[59] X. Wang, J. Zhou, S. Zhao, X. Chen, and Y. Yu, "Synergistic effect of adsorption and visible-light photocatalysis for organic pollutant removal over BiVO4/carbon sphere nanocomposites," Applied Surface Science, vol. 453, pp. 394-404, 2018.

[60] Y. Sheng, Z. Wei, H. Miao, W. Yao, H. Li, and Y. Zhu, "Enhanced organic pollutant photodegradation via adsorption/photocatalysis synergy using a 3D g-C3N4/TiO2 freeseparation photocatalyst," Chemical Engineering Journal, vol. 370, pp. 287-294, 2019. 